\title{
Upregulation of Aquaporin 2 Water Channel Expression in Pregnant Rats
}

\author{
Mamiko Ohara, Pierre-Yves Martin, Ding-Li Xu, Judy St. John, Timothy A. Pattison, Jin K. Kim, and Robert W. Schrier \\ Department of Medicine, University of Colorado Health Sciences Center, Denver, Colorado 80262
}

\begin{abstract}
Water retention is characteristic of pregnancy but the mechanism(s) of the altered water metabolism has yet to be elucidated. The collecting duct water channel, aquaporin 2 (AQP2), plays a pivotal role in the renal water regulation, and we hypothesized that AQP2 expression could be modified during pregnancy. Sprague-Dawley female rats were studied on days 7 (P7), 14 (P14), and 20 (P20) of pregnancy, and expression of $\mathrm{AQP} 2$ in papillae was examined. Nonpregnant (NP) littermates were used as controls. Plasma osmolalities were significantly lower in pregnant rats by day 7 of gestation ( $\mathrm{P} 7283.8 \pm 1.82, \mathrm{P} 14284.3 \pm 1.64, P<0.001, \mathrm{P} 20$ $282.4 \pm 1.32, P<0.0001$, vs. NP $\left.291.8 \pm 1.06 \mathrm{mosmol} / \mathrm{kgH}_{2} \mathrm{O}\right)$. However, plasma vasopressin concentrations in pregnant rats were not significantly different than in nonpregnant rats (NP 1.03 $\pm 0.14, \mathrm{P} 71.11 \pm 0.21, \mathrm{P} 141.15 \pm 0.21, \mathrm{P} 20$ $1.36 \pm 0.24 \mathrm{pg} / \mathrm{ml}, \mathrm{NS})$. The mRNA of AQP2 was increased early during pregnancy: $A Q P 2 / \beta$ actin: P7 196 \pm 17.9, P14 $200 \pm 6.8$, and P20 208 $\pm 15.5 \%, P<0.005$ vs. NP $(100 \pm$ $11.1 \%)$. AQP2 protein was also increased during pregnancy: AQP2 protein: P7 269 \pm 10.0, P14 251 $\pm 12.0, P<0.0001$, and P20 250 $\pm 13.6 \%, P<0.001$ vs. NP $(100 \pm 12.5 \%)$. The effect of V2 vasopressin receptor antagonist, OPC-31260, was then investigated. AQP2 mRNA was suppressed significantly by OPC-31260 administration to $\mathrm{P} 14$ rats $(\mathrm{AQP} 2 / \beta$ actin: P14 with OPC-31260 39.6 $\pm 1.7 \%, P<0.001$ vs. P14 with vehicle) and was decreased to the same level of expression as NP rats receiving OPC-31260. Similar findings were found with the analysis of AQP2 protein. The decreased plasma osmolality of P14 rats was not modified by OPC31260. The results of the study indicate that upregulation of AQP2 contributes to the water retention in pregnancy through a V2 receptor-mediated effect. In addition to vasopressin, other factors may be involved in this upregulation. (J. Clin. Invest. 1998. 101:1076-1083.) Key words: vasopressin • V2 vasopressin receptor antagonists - water retention $\bullet$ pregnancy $\bullet$ hypoosmolality
\end{abstract}

Part of this work was presented in abstract form at the 29th meeting of the American Society of Nephrology, 3-6 November, 1996, and subsequently published (1996. J. Am. Soc. Nephrol. 7:1271).

Address correspondence to Robert W. Schrier, M.D., Chairman, Department of Medicine, University of Colorado Health Sciences Center, 4200 East 9th Avenue, Denver, CO 80262. Phone: 303-3157765; FAX: 303-315-7702; E-mail: robert.schrier@uchsc.edu

Received for publication 15 May 1997 and accepted in revised form 19 December 1997.

J. Clin. Invest.

(c) The American Society for Clinical Investigation, Inc. 0021-9738/98/03/1076/08 \$2.00

Volume 101, Number 5, March 1998, 1076-1083

http://www.jci.org

\section{Introduction}

Pregnancy is characterized by a 30-50\% increase in extracellular fluid, plasma, and blood volume in different mammalian species, including humans and rats $(1,2)$. Whereas most of the water is isoosmotically retained, an associated hypoosmolality and hyponatremia are observed during the first trimester of pregnancy and are sustained until full term $(3,4)$. The mechanism of this water retention in pregnancy has been addressed in several investigations. The physiological situation of pregnancy is of particular interest, because while water retention and hypoosmolality of the degree observed in pregnancy suppress arginine vasopressin $(\mathrm{AVP})^{1}$ release and cause a water diuresis in the nonpregnant state, this is not the case in pregnancy (5). Indeed, AVP release has been demonstrated to be regulated normally around a new steady state of water retention, which suggests a "resetting" of the osmoreceptors during pregnancy $(3,6)$. In addition, it has been demonstrated that the osmotic threshold for thirst is also lower in pregnancy, thus facilitating the water retention (7). An alteration in the intrinsic sensitivity of the osmoreceptors and/or primary arterial vasodilation has been proposed for this resetting phenomenon of pregnancy $(2,8)^{*}$.

Recently, aquaporin 2 (AQP2), the vasopressin-sensitive water channel, has been cloned and located in the principal cells of the kidney collecting duct (9). Vasopressin stimulates water permeability of the apical membrane in the collecting duct, and recent reports indicate that vasopressin regulates AQP2 function and expression. Regulation of water transport across the renal principal cells depends on two mechanisms. First is the rapid action of AVP to increase the water permeability of the apical membrane of principal cells by translocating the AQP2 water channels from cytosolic vesicles to the plasma membranes $(10,11)$. This short-term effect is mediated by the V2 receptor-dependent increase of cAMP and may involve cAMP-dependent phosphorylation of AQP2 (12). Second, long-term regulation of collecting duct water permeability is characterized by an increase in AQP2 mRNA and protein content as illustrated in dehydrated rats (13) and by the infusion of AVP into diabetes insipidus (Brattleboro) rats (14). AQP2 protein appears to be more representative of the long-term regulation because of its stability and long half-life, compared with the AQP2 mRNA, which has a very short halflife (15).

In this study, we hypothesized that there is an increased expression of AQP2 water channels in pregnancy. Therefore, this study was undertaken to compare the AQP2 expression between nonpregnant and pregnant rats in renal inner medulla (papilla). To further elucidate the mechanism of AQP2 regulation during pregnancy, the effect of a nonpeptide V2 vaso-

1. Abbreviations used in this paper: AQP2, aquaporin 2; AVP, arginine vasopressin; NP, nonpregnant; P7, pregnant on day 7 of gestation; P14, pregnant on day 14 of gestation; P20, pregnant on day 20 of gestation. 
pressin receptor antagonist (OPC-31260) was examined on AQP2 expression, water excretion, and plasma osmolality in both nonpregnant and pregnant rats.

\section{Methods}

\section{Materials}

Sprague-Dawley pregnant and nonpregnant female rats aged 12-14 wk (Charles River Laboratories, Portage, MI) were used for all experiments. The rats were housed in a controlled environment and kept in filter-top microisolators. Animals were allowed free access to tap water and food (0.44\% sodium and $22.5 \%$ protein, ProLab 3000; Agway, Inc., Syracuse, NY) until the time of study. The protocol was approved by the University of Colorado Health Sciences Center Animal Care and Use Committee. Two female rats were housed with one male in the same cage for $3 \mathrm{~d}$. Determination of the gestational day was made by observation of the vaginal plug. The plug day was considered to be day zero. In the balance experiments, animals were housed individually in metabolic cages (Nalgene; Nalge Co., Rochester, NY). To acclimate them to the metabolic cages, rats were housed

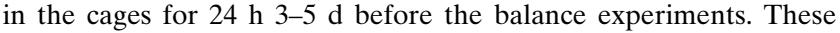
cages provide a good separation of urine and feces with the combination of a collecting funnel and a separating cone in the lower chamber. The urine was collected twice a day and frozen until analysis. Water and food intake were checked once a day. Animals in metabolic cages were subjected to 12-h light-dark cycles.

\section{Experimental protocols}

Protocol I: AQP2 gene expression in pregnant versus nonpregnant rats. On day 7 (P7), day 14 (P14), or day 20 (P20) of gestation (full term is 21-22 d), pregnant rats and paired nonpregnant (NP) rats were killed by decapitation to avoid any influence on AVP status by anesthesia. Trunk blood was collected, and kidneys were harvested and maintained on ice during dissection of the cortex and medulla. Papillae were carefully dissected from medulla, frozen, and stored in liquid nitrogen until extraction of total RNA and protein.

Protocol II: Effect of V2 vasopressin receptor antagonist, OPC31260, on AQP2 gene expression in NP versus pregnant (P14) rats. On day 11 of gestation, pregnant rats were housed individually in metabolic cages. Placebo or nonpeptide V2 receptor antagonist, 5-dimethylamino-1-[4-(2-methylbenzoylamino)-benzoyl]-2,3,4,5-tetrahydro-1H-benzazepine hydrochloride (OPC-31260; kindly provided by Otsuka America Pharmaceutical, Inc., Rockville, MD) was then administered by subcutaneous injection $(15 \mathrm{mg} / \mathrm{kg}$ twice per day) from day 11 to the morning of day 14 of gestation ( $72 \mathrm{~h}$ administration). A 24-h balance study was conducted from day 13 to day 14 of gestation. After the balance study, the rats received the last administration of placebo or OPC-31260, and were killed by decapitation $4 \mathrm{~h}$ later. Trunk blood was collected, and kidneys were harvested under ice. Groups of pregnant and NP rats were also examined after $42 \mathrm{~h}$ of OPC-31260 administration (from day 12 to day 14) to evaluate mRNA AQP2 expression.

Plasma sodium levels were measured using a CX3 analyzer (Beckman Instruments, Inc., Fullerton, CA), and plasma osmolalities were determined by freezing point depression (Advanced Instruments, Inc., Norwood, MA). Plasma AVP concentrations were measured by RIA as described previously (16). Rat AVP antibody (2849) for AVP RIA was generously provided by Dr. Jacques Durr (Veterans Affairs Medical Center, Bay Pines, FL).

\section{Northern blot analysis}

Total RNA from papillae was isolated from the aqueous phase of a simplified guanidium thiocyanate protocol using TRIzol Reagent (Life Technologies, Inc., Gaithersburg, MD). The total RNA (1.5-5 $\mu \mathrm{g}$ ) was then size-fractionated on a $1.0 \%$ agarose $/ 6 \%$ formaldehyde gel and subsequently transferred to a nylon membrane and ultraviolet cross-linked. The blots were prehybridized in Rapid-Hyb buffer
(Amersham Corp., Arlington Heights, IL) for $20 \mathrm{~min}$ at $65^{\circ} \mathrm{C}$ before addition of the labeled probe. The probe used for AQP2 consisted of an 850-bp segment from the rat gene as described previously (17). This probe was labeled using $\left[{ }^{32} \mathrm{P}\right] \mathrm{dCTP}$ and Redi-prime random primer labeling kit (Amersham Corp.), denatured by boiling for 5 min, and added to the prehybridization solution. The membranes were hybridized at $65^{\circ} \mathrm{C}$ for $2 \mathrm{~h}$ and then washed three times with $2 \times$ SSC and $0.1 \%$ SDS for $20 \mathrm{~min}$ at room temperature, and twice at $65^{\circ} \mathrm{C}$ for $30 \mathrm{~min}$ with $1 \times \mathrm{SSC}$ and $0.1 \%$ SDS. The membranes were exposed to BIOMAX MS film (Eastman Kodak Co., Rochester, NY) overnight at $-70^{\circ} \mathrm{C}$. Membranes were then hybridized to a cDNA fragment of $\beta$ actin gene which served as an internal control.

Densitometry results are reported as integrated values (area $\times$ density of the band), corrected by $\beta$ actin expression density, and expressed in percentage compared with the mean value in controls $(100 \%)$.

\section{Western blot analysis}

The rabbit polyclonal antibody against AQP2 was prepared by Genemed Biotechnologies, Inc. (South San Francisco, CA) using a synthetic peptide (CELHSPQSLPRGSKA) from the carboxy terminus of AQP2 (18). The peptide was conjugated to keyhole limpet hemocyanin by a cysteine sulfhydryl linkage. Test bleedings were screened by ELISA. Final titers were reported to be $>100,000$. Protein samples were obtained from the organic phase of the TRIzol reagent extraction procedure. Briefly, after removing the aqueous phase containing RNA, the interphase and the lower layer of phenol/ chloroform containing proteins were further purified. The DNA was precipitated with $100 \%$ ethanol and then removed. Proteins were precipitated with acetone, and the protein precipitate was sedimented at $5,000 \mathrm{~g}$ for $2 \mathrm{~min}$ at $4^{\circ} \mathrm{C}$. The pellet was dissolved in $1 \%$ SDS by sonication and spun at $5,000 \mathrm{~g}$ for $2 \mathrm{~min}$. The protein content of the supernatant for each sample was measured using the Bradford method (Bio-Rad Laboratories, Richmond, CA). The proteins were separated on denaturing SDS $12.5 \%$ polyacrylamide gels by electrophoresis as described previously (19). Proteins were then transferred to a polyvinylidene difluoride membrane (Millipore Corp., Bedford, MA) by wet electroblotting for $75 \mathrm{~min}$. Blots were blocked overnight at $4^{\circ} \mathrm{C}$ with $5 \%$ nonfat dry milk in TBS-T, pH 7.5 (20 mM Tris base, $137 \mathrm{mM} \mathrm{NaCl}, 0.1 \%$ Tween 20). Blots were incubated with AQP2 antibody (1:750 dilution) for $90 \mathrm{~min}$ at room temperature and then washed. Blots were then incubated with the second antibody (donkey anti-rabbit IgG conjugated with horseradish peroxidase, diluted 1:1,500; Amersham Corp.) for $1 \mathrm{~h}$. Subsequent detection of the specific proteins was carried out by enhanced chemiluminescence (ECL; Amersham Corp.) according to the manufacturer's instructions. To control for equal loading, the membranes were stained for Coomassie blue. Prestained protein markers (Sigma Chemical Co., St. Louis, MO) were used for molecular mass determinations. Some Western blots were performed with deglycosylated protein extract samples to demonstrate that the wide band seen between 35 and $45 \mathrm{kD}$ was the glycosylated AQP2 protein and not other nonspecific binding. These samples were deglycosylated by an 18 -h incubation with peptide $\mathrm{N} 4$ $(N$-acetyl- $\beta$ glucosaminyl) asparagine amidase $(N$-glycanase; Genzyme Corp., Cambridge, MA) at $37^{\circ} \mathrm{C}$.

Densitometry results are reported as integrated values (area $X$ density of the band) and expressed in percentage compared with the mean value in controls $(100 \%)$, corrected by total protein concentration.

\section{Immunohistochemistry}

Tissue blocks prepared from the kidney inner medulla were postfixed with $4 \%$ paraformaldehyde for $2 \mathrm{~h}$, then infiltrated with acrylamide, embedded in OCT compound, frozen in liquid nitrogen, and stored at $-80^{\circ} \mathrm{C}$ until further procedures were performed. Cryosections $(6 \mu \mathrm{m})$ cut on Tissue-TEK ${ }^{\circledR}$ cryostat (Miles Inc., Elkhart, IN) were collected on charged slides. After washing in PBS, the cryosections were first incubated with $0.1 \%$ Triton $\mathrm{X}$ for solubilizing the membranes, then 
Table I. Plasma Osmolality, Sodium Concentration, and Vasopressin Concentration in Pregnant and NP Rats

\begin{tabular}{lcccc}
\hline \multicolumn{1}{c}{ Group } & $n$ & $\begin{array}{c}\text { Plasma } \\
\text { osmolality }\end{array}$ & $\begin{array}{c}\text { Plasma } \\
\text { sodium }\end{array}$ & AVP \\
\hline & & mosmol/kgH $\mathrm{H}_{2} \mathrm{O}$ & $\mathrm{mM}$ & $\mathrm{pg} / \mathrm{ml}$ \\
Nonpregnant control & 17 & $291.8 \pm 1.06$ & $138.4 \pm 0.74$ & $1.03 \pm 0.14$ \\
Pregnant Day 7 & 18 & $283.8 \pm 1.82^{*}$ & $136.0 \pm 0.84^{\ddagger}$ & $1.11 \pm 0.21$ \\
Pregnant Day 14 & 12 & $284.3 \pm 1.64^{*}$ & $136.3 \pm 0.64^{\ddagger}$ & $1.15 \pm 0.21$ \\
Pregnant Day 20 & 12 & $282.4 \pm 1.32^{\S}$ & $134.9 \pm 0.42^{*}$ & $1.36 \pm 0.24$ \\
& & & &
\end{tabular}

Values are mean \pm SE. ${ }^{\ddagger} P<0.05, * P<0.001,{ }^{\S} P<0.0001$ pregnancy vs. nonpregnancy.

$0.5 \%$ BSA for blocking nonspecific binding, and then with the antibody against AQP2 (1:500) for $1 \mathrm{~h}$ at $37^{\circ} \mathrm{C}$. The labeling was visualized using fluorescein-conjugated goat anti-rabbit antibody, diluted 1:100 (Jackson ImmunoResearch Labs, West Grove, PA), and incubated for $1 \mathrm{~h}$ at $37^{\circ} \mathrm{C}$. Between each of these procedures, samples were washed in PBS three times for $5 \mathrm{~min}$ each at room temperature. Micrographs were taken on an Axiophot (Carl Zeiss, Berlin, Germany) at an original magnification of 197, using Ektachrome 400 (Eastman Kodak Co.) slide film.

\section{Statistical analysis}

Statistical analyses of plasma sodium, osmolality, AVP concentration, AQP $2 / \beta$ actin density ratio, and AQP2 density were performed using unpaired Student's $t$ test or ANOVA followed by $F$-Scheffé test post hoc. Results are expressed as mean \pm SE. $P<0.05$ was considered significant.

\section{Results}

Plasma sodium, osmolality, and AVP concentration in pregnant and NP rats (Table I). Plasma sodium and plasma osmolality were significantly lower in pregnant rats by day 7 of gestation and remained lower on days 14 and 20 than in NP rats. In spite of lower plasma osmolality, plasma AVP levels in pregnant rats measured by RIA were not suppressed compared with NP rats.

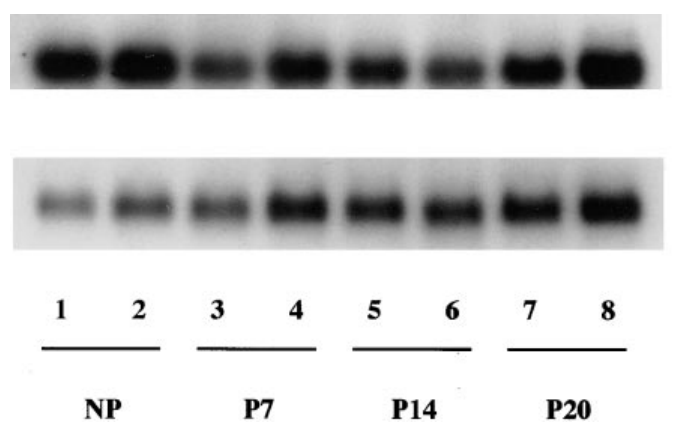

$\beta$ actin

AQP2

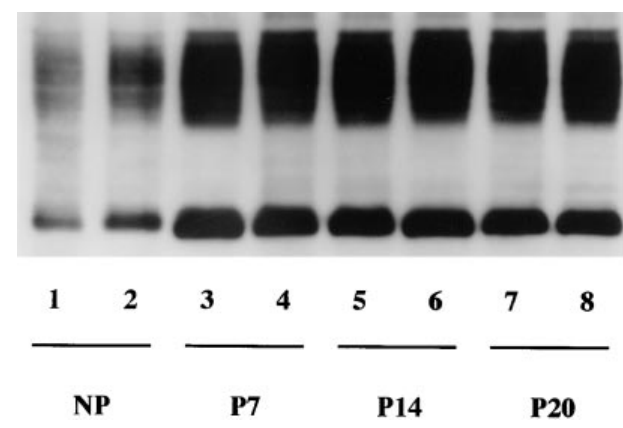

Figure 2. AQP2 protein expression is increased in pregnant rats on days 7,14 , and 20 of gestation compared with NP rats. Western blot analysis for AQP2 protein expressed in papilla using a polyclonal antibody against AQP2. $10 \mu \mathrm{g}$ of protein extract was loaded in each lane: lanes 1 and 2, NP rats; lanes 3 and 4, pregnant rats on day 7 of gestation; lanes 5 and 6 , pregnant rats on day 14 of gestation; lanes 7 and 8 , pregnant rats on day 20 of gestation. Two bands are detectable: a band of $29 \mathrm{kD}$ and a broader band of $36-45 \mathrm{kD}$ corresponding to the predicted molecular mass of AQP2 and its glycosylated form. 


\begin{tabular}{lcccc}
\hline \multicolumn{1}{c}{ Group } & Nonpregnant with vehicle & Nonpregnant with OPC-31260 & Pregnant with vehicle & Pregnant with OPC-31260 \\
\hline$n$ & 6 & 9 & 5 & 8 \\
Body weight $(\mathrm{g})$ & $234.3 \pm 6.04$ & $242.8 \pm 4.00$ & $269.7 \pm 9.59^{*}$ & $269.3 \pm 6.00^{\ddagger}$ \\
Water intake $(\mathrm{ml})$ & $42.0 \pm 2.33$ & $87.8 \pm 8.10^{\S}$ & $50.0 \pm 2.23$ & $98.7 \pm 1.81^{\|}$ \\
Food intake $(\mathrm{g})$ & $15.0 \pm 1.42$ & $17.4 \pm 0.82$ & $25.0 \pm 0.22^{*}$ & $22.7 \pm 0.69$ \\
Urine volume $(\mathrm{ml})$ & $19.8 \pm 1.58$ & $63.8 \pm 6.63^{\S}$ & $27.7 \pm 3.58$ & $74.3 \pm 4.06^{\|}$ \\
Plasma osmolality (mosmol/ $\left./ \mathrm{kgH}_{2} \mathrm{O}\right)$ & $290.8 \pm 1.05$ & $293.4 \pm 1.08$ & $282.8 \pm 3.15^{*}$ & $281.3 \pm 0.71^{\Uparrow}$ \\
Plasma sodium $(\mathrm{mM})$ & $139.3 \pm 0.49$ & $141.8 \pm 0.56$ & $135.0 \pm 0.89^{*}$ & $135.3 \pm 0.80^{\Uparrow}$ \\
Urine osmolality $\left(\mathrm{mosmol} / \mathrm{kgH}_{2} \mathrm{O}\right)$ & $1002.2 \pm 99.8$ & $409.3 \pm 43.7^{* *}$ & $984.8 \pm 124.4$ & $374.3 \pm 42.0^{\ddagger \ddagger}$ \\
AVP $(\mathrm{pg} / \mathrm{ml})$ & $1.02 \pm 0.12$ & $2.59 \pm 0.44^{\S}$ & $1.19 \pm 0.20$ & $2.76 \pm 0.44^{\|}$ \\
& & & & \\
\hline
\end{tabular}

Values are mean \pm SE. ${ }^{\S} P<0.05, * * P<0.001$ nonpregnant with OPC-31260 vs. nonpregnant with vehicle; $\| P<0.05$, ${ }^{\ddagger} P<0.001$ pregnant with OPC31260 vs. pregnant with vehicle; ${ }^{*} P<0.05$ pregnant with vehicle vs. nonpregnant with vehicle; ${ }^{\ddagger} P<0.05$, ${ }^{\mathbb{T}} P<0.0001$ pregnant with $\mathrm{OPC}-31620$ vs. nonpregnant with OPC-31260.

NP rats. The number of fetuses was not affected by OPC31260 administration (P14 with vehicle 12.1 \pm 0.81 , P14 with OPC-31260 12.3 \pm 0.66$)$.

Effect of OPC-31260 on AQP2 expression in pregnant and $N P$ rats. AQP2 mRNA expression in papilla from pregnant rats was suppressed significantly by OPC-31260 administration (AQP $2 / \beta$ actin density ratio: $\mathrm{P} 14$ with OPC-31260 39.6 $\pm 1.7 \%$, $P<0.001$ vs. P14 with vehicle $[100 \pm 9.2 \%] ; n=4$ in each group) (Fig. 3). AQP2 mRNA was decreased significantly by OPC 31260 administration in NP rats (AQP2/ $\beta$ actin density ratio: NP with OPC-31260 70.6 $\pm 4.1 \%, P<0.01$ vs. NP with vehicle $[100 \pm 6.6 \%] ; n=4$ in each group). The level of AQP2 mRNA expression was equalized in pregnant and NP rats treated by OPC-31260 administration (AQP $/ \beta$ actin density ratio: P14 with OPC-31260 103 $\pm 4.4 \%$, NS vs. NP with OPC$31260[100 \pm 5.9 \%] ; n=4$ in each group).

AQP2 protein expression in pregnant rats was decreased significantly by OPC-31260 administration (AQP2 protein density: P14 with OPC-31260 $45.4 \pm 5.8 \%, P<0.001$ vs. P14 with vehicle $[100 \pm 9.0 \%] ; n=5$ in each group) (Fig. $4 A$ ). AQP2 protein expression was decreased significantly in NP rats treated with OPC-31260 compared with NP rats treated

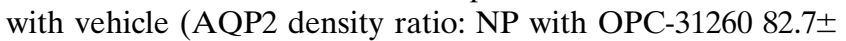
$3.3 \%, P<0.05$ vs. NP with vehicle $[100 \pm 5.7 \%] ; n=4$ in each group) (Fig. $4 \mathrm{~B}$ ). As with mRNA, administration of OPC31260 abolished the difference in AQP2 protein expression between pregnant and NP rats (AQP2 protein density: P14 with OPC-31260 98.9 $\pm 12.7 \%$, NS vs. NP with OPC-31260 $[100 \pm 3.9 \%])$.

Immunoreactivity of AQP2 with deglycosylated samples also showed similar results. Administration of OPC-31260 to pregnant rats decreased significantly AQP2 protein expression (AQP2 protein density: P14 with OPC-31260 37.2 $\pm 9.5 \%, P<$ 0.005 vs. P14 with vehicle [100 $\pm 7.4 \%] ; n=4$ in each group). AQP2 protein expression was decreased significantly in NP rats treated with OPC-31260 compared with NP rats treated with vehicle (AQP2 protein density ratio: NP with OPC-31260 $79.1 \pm 5.2 \%, P<0.05$ vs. NP with vehicle $[100 \pm 6.7 \%] ; n=4$ in each group). The level of deglycosylated AQP2 protein expression was equalized in pregnant and NP rats treated by OPC-31260 administration (AQP2 protein density: P14 with

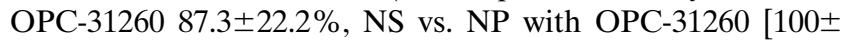
$6.5 \%] ; n=4$ in each group) (Fig. 5).

Immunohistochemistry studies results. Immunohistochemistry studies demonstrate that AQP2 water channels are located principally within the membrane in pregnant rats, implicating a functional effect of the increased content of AQP2 protein observed by Western blot. The labeling of AQP2 by immunofluorescence was seen exclusively in the collecting duct tubules. Immunofluorescence was distributed in an apical pattern, as illustrated by an intense linear staining, in inner medulla of P14 rats (Fig. 6 A). Administration of OPC-31260 to
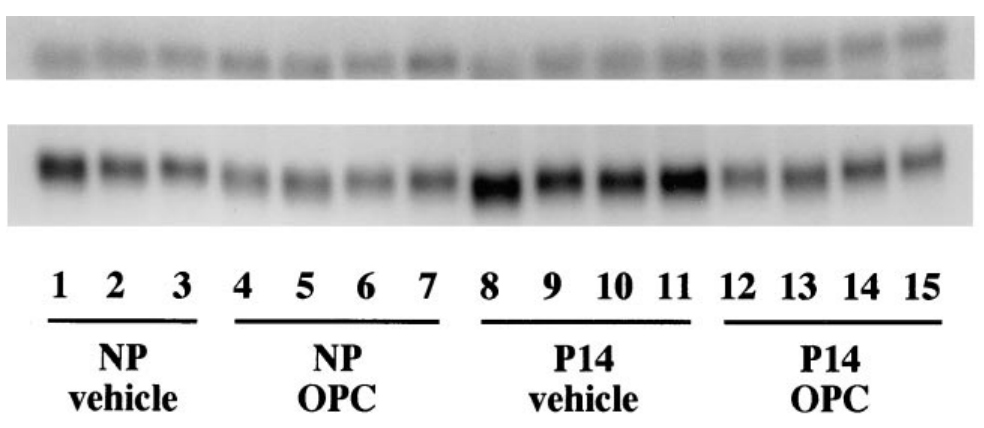

$\beta$ actin

Figure 3. Effect of the V2 vasopressin receptor antagonist OPC-31260 on AQP2 mRNA expression in pregnant and NP rats. Northern blot analysis of $1.5 \mu \mathrm{g}$ of total RNA from papilla: lanes 1,2 , and 3 , NP rats with vehicle; lanes 4, 5, 6, and 7, NP rats with OPC-31260; lanes $8,9,10$, and 11 , pregnant rats (day 14 of gestation) with vehicle; lanes $12,13,14$, and 15 ,

AQP2 pregnant rats (day 14 of gestation) with OPC31260. Hybridization to $\beta$ actin is also shown. AQP2 mRNA expression in both pregnant and NP rats was suppressed significantly by OPC-31260. The level of AQP2 mRNA expression was equalized in pregnant and NP rats treated by OPC-31260 administration. 
$\mathbf{A}$

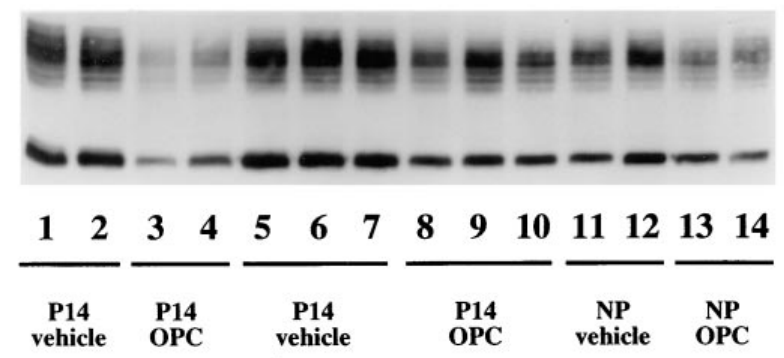

\section{$36-45 \mathrm{kD}$}

$29 \mathrm{kD}$

B

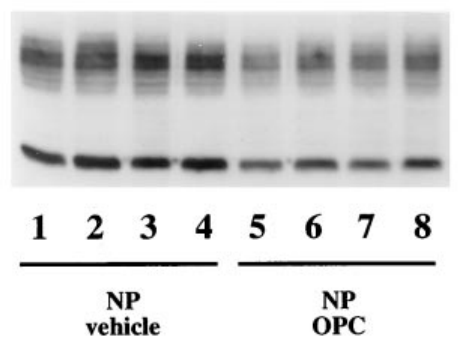

$36-45 \mathrm{kD}$

$29 \mathrm{kD}$

P14 rats resulted in a marked redistribution from the apical pattern to a punctuate labeling consistent with retrieval of water channel from the plasma membrane to the cytosol (Fig. 6B).

\section{Discussion}

There are several water channels which have been cloned and are distributed throughout the body (20). However, the AQP2 water channel is located only in the principal cells of the renal collecting ducts, the site where vasopressin-mediated water reabsorption occurs. During pregnancy, renal sodium and water retention result in an expansion of extracellular fluid by 30 $50 \%$ above the nonpregnant state (1-4). Moreover, the renal water retention is slightly greater than the sodium retention in pregnancy, thus causing a fall in plasma sodium and osmolality. Therefore, it is of interest to know whether AQP2 water channels are altered by pregnancy, and if so, when such an alteration occurs during gestation relative to the characteristic water retention of pregnancy.
Figure 4. Effect of the V2 vasopressin receptor antagonist OPC-31260 on AQP2 protein expression in pregnant and NP rats. Western blot analysis for AQP2 protein expressed in papilla using a polyclonal antibody against AQP2. $5 \mu \mathrm{g}$ of protein extract was loaded in each lane. $(A)$ Lanes 1,2, 5,6 , and 7 , pregnant rats (day 14 of gestation) with vehicle; lanes $3,4,8,9$, and 10 , pregnant rats (day 14 of gestation) with OPC-31260; lanes 11 and 12 , NP rats with vehicle; lanes 13 and 14, NP rats with OPC-31260. (B) Lanes 1,2,3, and $4, \mathrm{NP}$ rats with vehicle; lanes $5,6,7$, and $8, \mathrm{NP}$ rats with OPC-31260. AQP2 protein expression in both pregnant and NP rats was suppressed significantly by OPC-31260. The level of AQP2 protein expression was equalized in pregnant and NP rats treated by OPC-31260 administration.

The results of this investigation in the rat demonstrated that the mRNA for AQP2 is increased significantly in pregnancy. Moreover, Western blot analysis showed parallel increases in AQP2 protein in the pregnant compared with NP rats. The AQP2 mRNA and protein were increased significantly on day 7 of gestation, and further studies on days 14 and 20 demonstrated the persistence of this rise throughout gestation.

It is known that AVP shuttles AQP2 water channels to the apical membrane of the principal collecting duct cells $(10,11)$ and that chronic AVP stimulates AQP2 mRNA and protein (14). However, results of plasma AVP concentrations in pregnancy have demonstrated no difference from the nonpregnant state (21), and in this study, there were no detectable differences in plasma AVP concentrations between the pregnant and NP rats. To our knowledge, these results in pregnancy are the first clinical situation where a significant increase in AQP2 expression has been demonstrated in the absence of a detectable increase in plasma AVP concentrations. Therefore, our

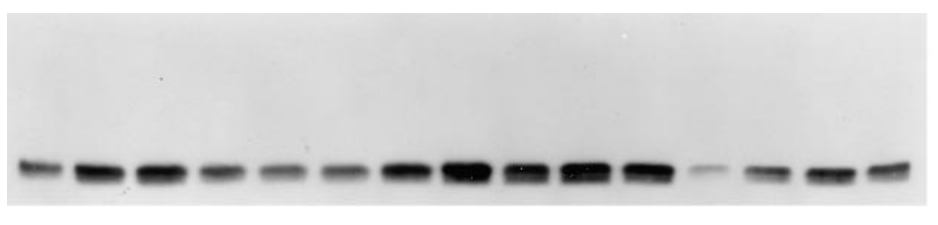

36-45 kD

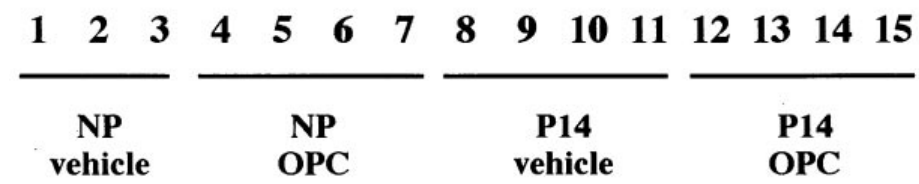

Figure 5. Effect of the V2 vasopressin receptor antagonist OPC-31260 on deglycosylated AQP2 protein expression in pregnant and NP rats. Western blot analysis for AQP2 protein expressed in papilla using a polyclonal antibody against AQP2. $2 \mu \mathrm{g}$ of protein extract was deglycosylated with peptide $\mathrm{N} 4$ asparagine amidase and loaded in each lane: lanes 1,2 , and $3, \mathrm{NP}$ rats with vehicle; lanes $4,5,6$, and $7, \mathrm{NP}$ rats with OPC-31260; lanes 8, 9, 10, and 11, pregnant rats with vehicle; lanes $12,13,14$, and 15 , pregnant rats with OPC-31260. Deglycosylating the protein extracts eliminated the broad band

between 36 and $45 \mathrm{kD}$, leaving only the band corresponding to the molecular mass of AQP2 (29 kD). Deglycosylated AQP2 protein expression in both pregnant and NP rats was suppressed significantly by OPC-31260. The level of deglycosylated AQP2 protein expression was equalized in pregnant and NP rats treated by OPC-31260 administration. 


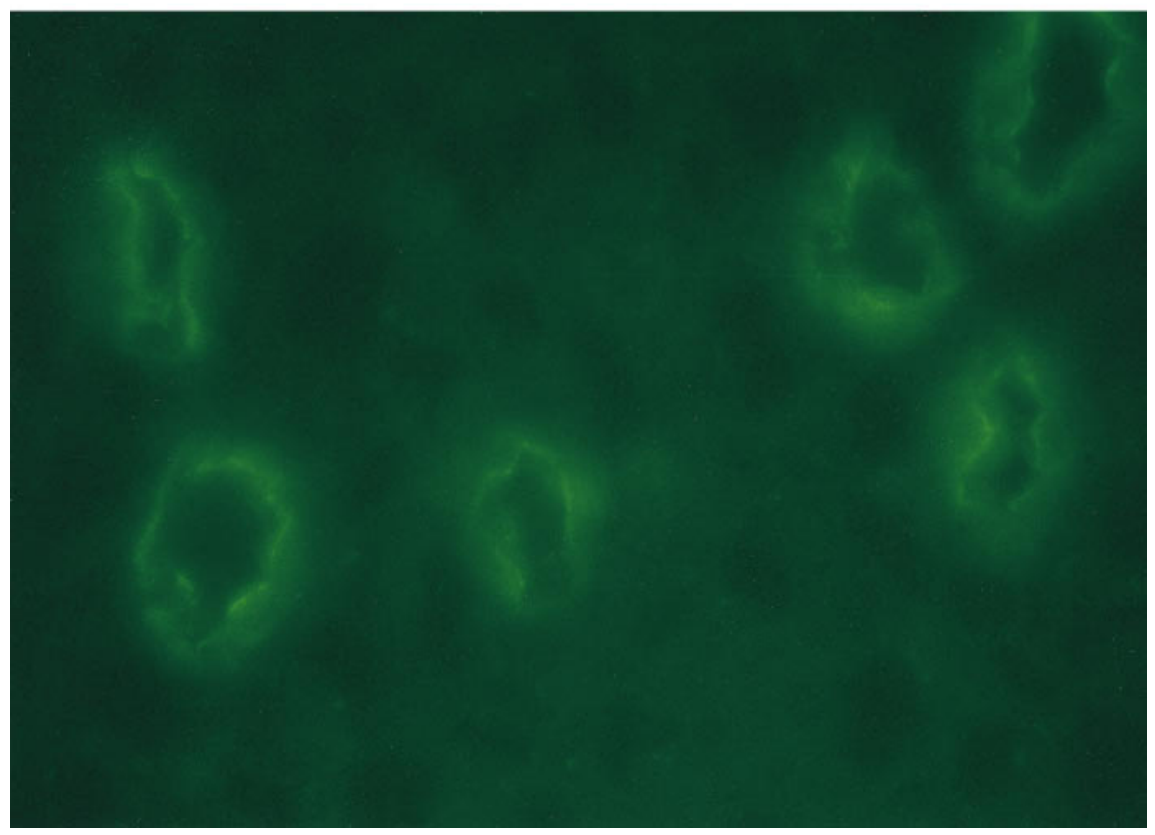

B

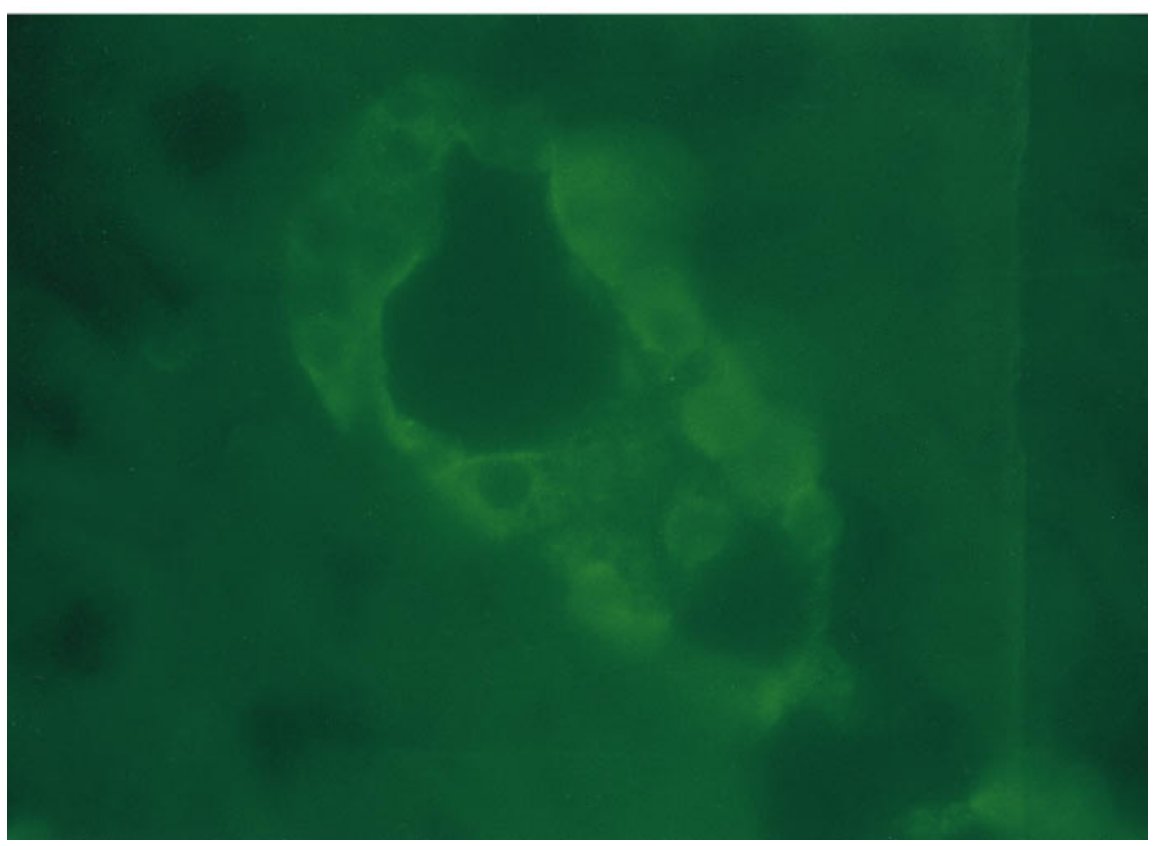

Figure 6. Immunofluorescence of AQP2 protein in inner medulla from $(A)$ pregnant rats treated with vehicle, or $(B)$ pregnant rats treated with OPC-31260 $(\times 197)$. Pregnant rats treated with vehicle are characterized by an intense apical pattern of distribution of AQP2. Pregnant rats treated with OPC31260 show redistribution in vesicles widely dispersed throughout the cytoplasm compatible with the retrieval of AQP2 from the apical membrane.

findings raise the possibility that a non-AVP factor occurring during pregnancy may "reset" the AQP2 water channels in the collecting duct, as has been shown for the osmotic threshold for AVP and thirst (7). However, the absence of detectable differences in plasma AVP concentrations does not definitively exclude a role of AVP, because it is known that a small exogenous infusion of AVP which is not accompanied by a detectable rise in plasma AVP concentration can cause renal water retention (22). To evaluate these possibilities, we administered a nonpeptide V2 vasopressin antagonist, OPC-31260, which has been used to assess the in vivo role of AVP.
The V2 vasopressin antagonist was administrated to the pregnant and NP rats for $72 \mathrm{~h}$ at $14 \mathrm{~d}$ of gestation, and a balance study was performed during the last $24 \mathrm{~h}$. The studies were performed on day 14 of gestation to avoid any early or late changing events, and after $72 \mathrm{~h}$ of antagonist treatment to provide enough time to detect a change in AQP2 protein. The V2 antagonist was effective and led to a diuresis and urinary dilution in both pregnant and NP rats. Immunohistochemistry studies demonstrate the retrieving of AQP2 water channels from the apical membrane to the subapical cytosol during the antagonist administration. The OPC-31260 (30 mg/kg/d) ad- 
ministration was also associated with a decrease in the AQP2 protein that was significantly greater in the pregnant than in the NP rats. Most importantly, the AQP2 proteins were not detectably different between the pregnant and NP rats after $72 \mathrm{~h}$ of the $\mathrm{V} 2$ receptor antagonist. The same quantitative effect of OPC-31260, although less marked, was observed at $42 \mathrm{~h}$ when AQP2 mRNA was examined by Northern blot analysis. Therefore, these results appear to incriminate the V2 vasopressin receptors in the increase in AQP2 water channels observed during pregnancy. Because the $\mathrm{V} 2$ receptors are regulated principally by AVP, our findings are compatible with this hormone as a cause of this AQP2 upregulation, even without a detectable increase in plasma concentration (22). However, another possibility is the occurrence of vasopressin-independent upregulation of AQP2 water channels in pregnancy. Indeed, Chou et al. $(23,24)$ have shown that oxytocin causes an antidiuresis by activating the V2 receptors in the collecting duct, an effect that can be blocked by a V2 vasopressin receptor antagonist. Thus, the antidiuretic action of oxytocin is mediated through the V2 receptor. Plasma oxytocin concentrations before labor have been reported to be increased during pregnancy, but the results have been variable due to the different methodologies used $(25,26)$. There might be other unknown factors contributing to this upregulation.

Another interesting finding in this study was the persistence of the hypoosmolality in pregnancy after $72 \mathrm{~h}$ of the V2 vasopressin antagonist administration and comparable AQP2 water channel expression in the pregnant and NP animals. This finding indicates that the hypoosmolality of pregnancy can occur independently of vasopressin-mediated effects of the collecting duct water channels. The most likely possibility for this persistent hypoosmolality in pregnancy despite the V2 receptor blockade is the polydipsia of pregnancy. In support of this interpretation is the observation that homozygous Brattleboro rats demonstrated the same lowering of plasma osmolality during pregnancy despite the absence of detectable circulating AVP $(6,27)$. Moreover, angiotensin activity is increased during pregnancy (28), and the role of angiotensin II in the control of thirst has been well-established (29). Finally, because of the peripheral vasodilation and the resultant arterial underfilling, vasopressin-independent factors such as increased thirst may be more important in affecting water retention in pregnancy than in the nonpregnant state.

In summary, the results of this study in rats demonstrate the upregulation of both the AQP2 mRNA and protein in pregnancy without a concomitant significant increase in plasma AVP concentration. This effect occurs early in gestation (day 7) and persists throughout pregnancy. This upregulation of AQP2 that occurred in pregnancy has also been observed in another state of peripheral arterial vasodilation, cirrhosis (30), as well as in the arterial underfilling due to cardiac failure (17), but in association with elevated plasma AVP concentrations. The results with the $\mathrm{V} 2$ vasopressin antagonist which reversed the AQP2 upregulation potentially incriminate the role of the $\mathrm{V} 2$ receptor in this effect of pregnancy on the collecting duct water channels. The AQP2 gene 5'-flanking region has a cAMP-response element that likely explains the action of the V2 receptor to increase the transcription rate of AQP2 $(31,32)$. Whether this effect is mediated by AVP or by an AVP-independent factor such as oxytocin has yet to be determined. Finally, the persistent hypoosmolality of pregnancy in the presence of $\mathrm{V} 2$ receptor blockade suggests a role for
non-AVP factors, such as the increased polydipsia of pregnancy, in the solute-free water retention.

\section{Acknowledgments}

We would like to thank Dr. Jacques Durr for providing the rat AVP antibody (2849) for AVP RIA, and Otsuka America Pharmaceutical, Inc., for providing the V2 receptor antagonist, OPC-31260. We are deeply indebted to Dr. Yoshitaka Yamamura for his expert advice on the V2 receptor antagonist, Sandra Summer for her advice on plasma vasopressin concentration measurements, and Carole Hildebrandt for her assistance with sodium and osmolality measurements. We are also thankful to Dr. Ryuji Higashita for his assistance with animal handling.

This work was performed in the Department of Medicine, University of Colorado Health Sciences Center, and was supported by a grant from the National Institutes of Health (DK-19928). P.-Y. Martin was supported by a grant from the Eugenio Litta Foundation, Geneva, Switzerland. D.-L. Xu was supported by a fellowship award from the International Society of Nephrology.

\section{References}

1. Phippard, A.F., J.S. Horvath, E.M. Glynn, M.G. Garner, P.J. Fletcher, G.G. Duggin, and D.J. Tiller. 1986. Circulatory adaptation to pregnancy-serial studies of haemodynamics, blood volume, renin and aldosterone in the baboon (Papio hamadryns). J. Hypertens. 4:773-779.

2. Schrier, R.W., and V.A. Briner. 1991. Peripheral arterial vasodilation hypothesis of sodium and water retention in pregnancy: implications for pathogenesis of preeclampsia-eclampsia. Obstet. Gynecol. 77:632-639.

3. Davison, J.M., M.B. Vallotton, and M.D. Lindheimer. 1981. Plasma osmolality and urinary concentration and dilution during and after pregnancy: evidence that lateral recumbency inhibits maximal urinary concentrating ability. Br. J. Obstet. Gynaecol. 88:472-479.

4. Robson, S.C., S. Hunter, R.J. Boys, and W. Dunlop. 1989. Serial study of factors influencing changes in cardiac output during human pregnancy. Am. J. Physiol. 232:H1060-H1065.

5. Lindheimer, M.D., and J.M. Davison. 1995. Osmoregulation, the secretion of arginine vasopressin and its metabolism during pregnancy. Eur. J. Endocrinol. 132:133-143.

6. Durr, J.A., B. Stamoutsos, and M.D. Lindheimer. 1981. Osmoregulation during pregnancy in the rat. Evidence for resetting of the threshold for vasopressin secretion during gestation. J. Clin. Invest. 68:337-346.

7. Davison, J.M., E.A. Shiells, P.R. Philips, and M.D. Lindheimer. 1988. Serial evaluation of vasopressin release and thirst in human pregnancy. Role of human chorionic gonadotrophin in the osmoregulatory changes of gestation. $J$. Clin. Invest. 81:798-806.

8. Schrier, R., T. Berl, and R. Anderson. 1979. Osmotic and nonosmotic control of vasopressin release. Am. J. Physiol. 236:F321-F332.

9. Fushimi, K., S. Uchida, Y. Hara, Y. Hirata, F. Marumo, and S. Sasaki. 1993. Cloning and expression of apical membrane water channel of rat kidney collecting tubule. Nature. 361:549-552.

10. Nielsen, S., C.L. Chou, D. Marples, E.I. Christensen, B.K. Kishore, and M.A. Knepper. 1995. Vasopressin increases water permeability of kidney collecting duct by inducing translocation of aquaporin-CD water channels to plasma membrane. Proc. Natl. Acad. Sci. USA. 92:1013-1017.

11. Yamamoto, T., S. Sasaki, K. Fushimi, K. Ishibashi, E. Yaoita, K. Kawasaki, F. Marumo, and I. Kihara. 1995. Vasopressin increases AQP-CD water channel in apical membrane of collecting duct cells in Brattleboro rats. Am. J. Physiol. 268:C1546-C1551.

12. Kuwahara, M., K. Fushimi, Y. Terada, L. Bai, F. Marumo, and S. Sasaki. 1995. cAMP-dependent phosphorylation stimulates water permeability of aquaporin-collecting duct water channel protein expressed in Xenopus oocytes. J. Biol. Chem. 270:10384-10387.

13. Yamamoto, T., S. Sasaki, K. Fushimi, K. Kawasaki, E. Yaoita, K. Oota, Y. Hirata, F. Marumo, and I. Kihara. 1995. Localization and expression of a collecting duct water channel, aquaporin, in hydrated and dehydrated rats. Exp. Nephrol. 3:193-201.

14. DiGiovanni, S.R., S. Nielsen, E.I. Christensen, and M.A. Knepper. 1994 Regulation of collecting duct water channel expression by vasopressin in Brattleboro rat. Proc. Natl. Acad. Sci. USA. 91:8984-8988.

15. Saito, T., S. Ishikawa, S. Sasaki, N. Fujita, K. Fushimi, K. Okada, K. Takeuchi, A. Sakamoto, S. Ookawara, T. Kaneko, et al. 1997. Alteration in water channel AQP-2 by removal of AVP stimulation in collecting duct cells of dehydrated rats. Am. J. Physiol. 272:F183-F191.

16. Kim, J.K., S.N. Summer, R.L. Howard, and R.W. Schrier. 1993. Vaso- 
pressin gene expression in rats with experimental cirrhosis. Hepatology. 17: $143-147$

17. Xu, D.-L., P.-Y. Martin, M. Ohara, J. St. John, T. Pattison, X. Meng, K. Morris, J.K. Kim, and R.W. Schrier. 1997. Upregulation of aquaporin-2 water channel expression in chronic heart failure rat. J. Clin. Invest. 99:1500-1505.

18. Nielsen, S., S.R. DiGiovanni, E.I. Christensen, M.A. Knepper, and H.W. Harris. 1993. Cellular and subcellular immunolocalization of vasopressinregulated water channel in rat kidney. Proc. Natl. Acad. Sci. USA. 90:1166311667.

19. Burnette, W.N. 1981. Western blotting: electrophoretic transfer of proteins from SDS-polyacrylamide to unmodified nitrocellulose and radiographic detection with antibody and radiolabeled protein A. Anal. Biochem. 112:195-203.

20. King, L.S., and P. Agre. 1996. Pathophysiology of the aquaporin water channels. Annu. Rev. Physiol. 58:619-648.

21. Barron, W.M., and M.D. Lindheimer. 1988. Osmoregulation in pseudopregnant and prolactin-treated rats: comparison with normal gestation. Am. J. Physiol. 254:R478-R484.

22. Andersen, L.J., J.L. Andersen, H.J. Schutten, J. Warberg, and P. Bie. 1990. Antidiuretic effect of subnormal levels of arginine vasopressin in normal humans. Am. J. Physiol. 259:R53-R60.

23. Chou, C.L., S.R. DiGiovanni, R. Mejia, S. Nielsen, and M.A. Knepper. 1995. Oxytocin as an antidiuretic hormone. I. Concentration dependence of action. Am. J. Physiol. 269:F70-F77.

24. Chou, C.L., S.R. DiGiovanni, A. Luther, S.J. Lolait, and M.A. Knepper. 1995. Oxytocin as an antidiuretic hormone. II. Role of V2 vasopressin receptor.
Am. J. Physiol. 269:F78-F85.

25. Dawood, M.Y., and F.S. Khan-Dawood. 1985. Oxytocin. In Clinical Reproductive Endocrinology. R.P. Shearman, editor. Churchill Livingstone, Inc. New York. 233-248

26. Yen, S.S.C. 1991. The hypothalamic control of pituitary hormone secretion. In Reproductive Endocrinology. S.S.C. Yen and R.B. Jaffe, editors. W.B. Saunders Co., Philadelphia. 65-104.

27. Barron, W.M., J. Durr, B.A. Stamoutsos, and M.D. Lindheimer. 1985. Osmoregulation and vasopressin secretion during pregnancy in Brattleboro rats. Am. J. Physiol. 248:R29-R37.

28. Conrad, K.P., P.M. Morganelli, T. Brinck-Johnsen, and M.C. Colpoys. 1989. The renin-angiotensin system during pregnancy in chronically instrumented, conscious rats. Am. J. Obstet. Gynecol. 161:1065-1072.

29. Fitzsimons, J.T., and B.J. Simons. 1969. The effect on drinking in the rat of intravenous infusion of angiotensin, given alone or in combination with other stimuli of thirst. J. Physiol. (Lond.). 203:45-57.

30. Asahina, Y., N. Izumi, N. Enomoto, S. Sasaki, K. Fushimi, F. Marumo, and C. Sato. 1995. Increased gene expression of water channel in cirrhotic rat kidneys. Hepatology. 21:169-173.

31. Uchida, S., S. Sasaki, K. Fushimi, and F. Marumo. 1994. Isolation of human aquaporin-CD gene. J. Biol. Chem. 269:23451-23455.

32. Yasui, M., S.M. Zelenin, G. Celsi, and A. Aperia. 1997. Adenylate cyclase-coupled vasopressin receptor activates AQP2 promoter via a dual effect on CRE and AP1 elements. Am. J. Physiol. 272:F443-F450. 